Pak. j. sci. ind. res. Ser. B: biol. sci. 201255 (3) 154-158

\title{
Detoxification of Aflatoxin B1 in Poultry and Fish Feed by Various Chemicals
}

\author{
Alim-un-Nisa ${ }^{a *}$, Naseem Zahra ${ }^{b}$, Sajila Hina ${ }^{a}$ and Nusrat Ejaz $^{a}$ \\ ${ }^{a}$ Food and Biotechnology Research Centre, PCSIR, Laboratories Complex, Ferozepur Road, \\ Lahore-54600, Pakistan \\ bPakistan Institute of Technology for Minerals \& Advanced Engineering Materials, \\ PCSIR, Laboratories Complex, Ferozepur Road, Lahore-54600, Pakistan
}

(received February 22, 2012; revised June 20, 2012; accepted July 13, 2012)

\begin{abstract}
In this study various poultry and fish feed samples were initially analyzed for presence of aflatoxin. All the samples were found contaminated with aflatoxin B1 only. Contaminated samples were treated with different organic and inorganic chemicals to detoxify aflatoxin B1 in poultry and fish feed samples. The maximum reduction in the aflatoxin B1 concentration was observed with $0.5 \% \mathrm{HCl}$ as 14.20 ppb to $2.09 \mathrm{ppb}(86.50 \%)$ in the poultry and $69.26 \mathrm{ppb}$ to $10.46 \mathrm{ppb}(84.89 \%)$ in fish feed samples.
\end{abstract}

Keywords: aflatoxin, detoxification, chemicals, thin layer chromatography

\section{Introduction}

Aflatoxins are harmful substances that can cause severe health hazards to human and animals due to which many economical problems originate. The contamination of animal feed with mycotoxins represents a worldwide problem for farmers. These toxins originate from molds whose growth on living and stored plants is almost unavoidable particularly under moist conditions (Alexander et al., 2001). The fungal species Aspergillus flavus and Aspergillus parasiticus are very harmful for food and feed stuff, therefore the removal of these aflatoxins is extremely necessary. A close relationship exists between the quality of feed and the quality of animal products offered for human consumption. However, feeds can also be contaminated with a wide variety of compounds (Frank, 2011). Various chemicals have been used to kill pathogens in feed and feed ingredients. The detoxification effect of citric acid was investigated in rice samples and the results revealed the effectiveness of $1 \mathrm{~N}$ citric acid in reducing aflatoxins levels in rice samples (Safara et al., 2010). Some countries adjust aflatoxin levels in their foods e.g. USA and EU (Europe Union) permit level lower than $20 \mathrm{ppb}$ and Korea and Japan 10 ppb (Chiavaro et al., 2001). The alkali treatment using inorganic or organic bases is an effective and economically feasible method of degrading aflatoxins. Treatment of corn with less than

*Author for correspondence; E-mail: nisaalim64@yahoo.com
0.5\% calcium hydroxide decreased aflatoxin levels by $43 \%$ and boiling $1600-p p b$ naturally contaminated corn with $3 \%$ sodium hydroxide at $100{ }^{\circ} \mathrm{C}$ for 4 min decreased total aflatoxins levels by $93 \%$ (Hamed, 2005). Detoxification of aflatoxins in the poultry mixed feed naturally contaminated at the level of $775.25 \mathrm{ppb}$ was done using chemicals, viz. sodium bisulphite and sodium hydroxide (Singh et al., 2003). Aflatoxins can be destroyed with calcium hydroxide (Bauer, 1994). Reduction to less than $10 \%$ of the original AFB1 content within $2 \mathrm{~h}$ was recorded when the medium contained $1.5 \%$ potassium permanganate, 2.5 and $5 \%$ chloramin B (lachema) or soda, and when there was $5 \%$ ammonia heated to $60{ }^{\circ} \mathrm{C}, 5 \%$ sodium hydroxide, potassium hydroxide or calcium hydroxide, or $50 \%$ chromosulphuric acid (Dvorak, 1990). Several compounds such as activated charcoal, aluminosilicates and processed cell wall of Saccharomyces sp. (esterified glucomannan) have shown to be effective as mycotoxin adsorbents in poultry feeds (Vieira, 2003). Chemical detoxification methods such as use of hydrogen peroxide (Sreenivasa et al., 1967) and calcium hydroxide (Coker et al., 1984), sodium hydroxide and ammonification have been investigated. Ammonia treatment was found to be the most effective and practical method for use in large scale feed processing plants with $95 \%$ of successful detoxification. Aflatoxin-contaminated commodities can be detoxified by a variety of methods based to some extent on economics and the physical and chemical 
characteristics of the substance being treated. In this study, use of different chemicals is evaluated for the detoxification of aflatoxin B1 in the contaminated samples of poultry and fish feed.

\section{Materials and Methods}

This study was conducted in Food and Biotechnology Research Centre of Pakistan Council of Scientific and Industrial Research Laboratories Complex, Lahore. The poultry and fish feed samples were prepared for aflatoxin analysis by method of Begum et al. (1985). Aflatoxins were detected by Romer's method (Romer et al., 1976). Estimation of aflatoxins in toxic extracts was made by comparison with standard technique (AOAC, 2005). Analytical laboratories use one of several procedures such as thin-layer chromatography, mini columns, gas chromato-graphy, or mass spectroscopy to determine aflatoxin levels. These procedures are highly accurate and quantitative. In this study thin layer chromatographic (TLC) technique was used for the determination of aflatoxin in all samples.

Materials. In the present study, all the chemicals used were of analytical grade procured from BDH (Poole, England), Merck (Darmstadt, Germany) and Sigma Chemicals (St. Louis, USA).

Preparation of samples for aflatoxins determination. Extract. The half laboratory sample was ground through Romer grinding mill. The other half sample was kept for reference. The ground sample was mixed properly and test portion was taken from this mixture. $50 \mathrm{~g}$ of ground sample was taken into $500 \mathrm{~mL}$ conical flask and $25 \mathrm{~mL}$ of water, $25 \mathrm{~g}$ diatomaceous earth and $150 \mathrm{~mL}$ chloro-form was added. After shaking for $30 \mathrm{~min}$ filtered through filter paper. Collected $2^{\text {nd }} 50 \mathrm{~mL}$ portion $\mathrm{CHCl}_{3}$ and evaporated on a steam bath.

Qualitative determination. Immediately spotted 5, 10 and $15 \mu \mathrm{L}$ on TLC plate (Approximately $1.5 \mathrm{~cm}$ from the base). Spotted $5 \mu \mathrm{L}$ standard on one spot in a duplicate as internal standard. The plate was developed with anhydrous ether in developing tank uptill half. After development in ether removed the plate from tank and let it dry. Redeveloped in same direction in TLC tank with acetone-chloroform (1:9) (v/v). Adjusted the acetone-chloroform ratio as needed to modify $R_{f}$ of aflatoxins. Finally presence or absence of aflatoxins in test solution spot was observed.

Quantitative determination. For Quantitative analysis 1, 2, 3, 4 and $5 \mu \mathrm{L}$ of test solution was spotted on silica gel coated plates. Similarly on same plate 1, 2, 3, 4 and $5 \mu \mathrm{L}$ of aflatoxin standard was spotted. The fluorescence intensities of the spots were compared and the concentration of aflatoxins was calculated by applying the following formula

Aflatoxins $(\mu \mathrm{g} / \mathrm{kg})=\frac{\mathrm{S} \times \mathrm{Y} \times \mathrm{V}}{\mathrm{W} \times \mathrm{Z}}$

Where:

$\mathrm{Z}=$ Volume in $\mu \mathrm{L}$ of sample extract required to give fluorescence intensity comparable to that of $\mathrm{S}=\mu \mathrm{L}$ of aflatoxins standard

$\mathrm{S}=$ Volume in $\mu \mathrm{L}$ of aflatoxins standard of equivalent intensity to $\mathrm{Z}$ ( $\mu \mathrm{L}$ of sample) $\mathrm{Y}=$ Concentration of aflatoxins standard in $\mu \mathrm{g} / \mathrm{mL}$ $\mathrm{V}=$ Volume in $\mu \mathrm{L}$ of solvents required to dilute final extract

$\mathrm{W}=$ Weight in $\mathrm{g}$ of original sample contained in final extract

Detoxification. There are many methods for detoxification of aflatoxins. Aflatoxins can be detoxified physically (sunlight), biologically (bacteria, soil) and chemically (Basappa and Shantha, 1996). In this study aflatoxins positive samples were detoxified by the treatment of different chemical solutions.

Detoxification by various chemicals. Ground samples (50 g) were kept into different $500 \mathrm{~mL}$ conical flasks. Chemical solutions of different compositions of $\mathrm{HCl}$, $\mathrm{CaOH}$, citric acid, Iso-propanol, sodium hypochlorite, sodium bisulphate, acetone and ethanol were added into different flasks. Conical flasks were shaken on wrist action shaker for $2 \mathrm{~h}$ and then filtered through filter paper and dried for 2 days.

Quantification after detoxification. Quantification of detoxified sample for aflatoxins was carried out by same method such as chloroform extraction, detection by thin layer chromatography, estimation through UV light and calculation by formula.

\section{Results and Discussion}

Aflatoxins are among the most powerful carcinogens, naturally occurring fungal toxic metabolites and pose significant health risks and acute toxicological effects to human beings as well as animals. Approximately 20 aflatoxins have been isolated from various fungal species. Among these aflatoxin B1 is most toxic and potent. Aflatoxin B1 received greater attention than any other mycotoxins because of its demonstrable carcinogenic 
effect in susceptible animals and its acute toxic effects in human (Bressac et al., 1991). The detoxification of aflatoxin B1 in poultry feed samples by using different chemicals is shown in Table 1.

It was observed that aflatoxin B1 is greatly reduced by $0.5 \%$ hydrochloric acid (Table 1 ) while no reduction in aflatoxin B1 was observed when 1\% Iso-propanol was used in poultry feed samples. 50\% calcium hydroxide and $0.4 \%$ sodium hypochlorite may be effective as detoxifying chemicals for aflatoxin B1 as $80 \%$ and $82.98 \%$ reduction of aflatoxin $\mathrm{B} 1$ was noted, respectively. There was no reduction of aflatoxin B1 in fish feed samples when $1 \%$ and $2 \%$ Iso-propanol were used as detoxifying chemicals. In case of fish feed samples $0.4 \%$ sodium hypochlorite reduced aflatoxin B1 upto 80.97\% while $77.84 \%$ reduction in aflatoxin was observed when $50 \%$ calcium hydroxide was used (Table 2).

Table 1. Detoxification of aflatoxin B1 in poultry feed samples by using different chemicals

\begin{tabular}{|c|c|c|c|c|}
\hline $\begin{array}{l}\text { Poultry feed } \\
\text { samples }\end{array}$ & $\begin{array}{l}\text { Aflatoxin B1 } \\
\text { (ppb) }\end{array}$ & $\begin{array}{l}\text { Solvent used for } \\
\text { detoxification } \\
\text { (\%) }\end{array}$ & $\begin{array}{l}\text { Aflatoxin B1 } \\
\text { (ppb) after } \\
\text { treatment }\end{array}$ & $\begin{array}{l}\text { Reduction } \\
\text { in aflatoxin } \\
(\%)\end{array}$ \\
\hline 1. & $\mathrm{~B} 1=0.73$ & 0.1 Hydrochloric acid & $\mathrm{B} 1=0.49$ & 32.80 \\
\hline 2. & $\mathrm{~B} 1=15.20$ & 0.3 Hydrochloric acid & $\mathrm{B}_{2}=7.70$ & 49.30 \\
\hline 3. & $\mathrm{~B}_{1}=14.20$ & 0.5 Hydrochloric acid & $\mathrm{B}_{1}=2.09$ & 86.50 \\
\hline 4. & $\mathrm{~B}_{1}=4.30$ & 5 Calcium hydroxide & $\mathrm{B}_{1}=1.23$ & 71.39 \\
\hline 5. & $\mathrm{~B}_{1}=25.80$ & 50 Calcium hydroxide & $\mathrm{B}_{1}=5.16$ & 80.00 \\
\hline 6. & $\mathrm{~B} 1=3.14$ & 10 Citric acid & $\mathrm{B} 1=2.08$ & 33.00 \\
\hline 7. & $\mathrm{~B}_{1}=7.70$ & 30 Citric acid & $\mathrm{B}_{1}=2.80$ & 63.00 \\
\hline 8. & $\mathrm{~B} 1=4.38$ & 1 Iso-propanol & $\mathrm{B} 1=4.38$ & 0.00 \\
\hline 9. & $\mathrm{~B}_{1}=11.70$ & 5 Iso-propanol & $\mathrm{B}_{1}=10.89$ & 6.90 \\
\hline 10. & $\mathrm{~B}_{1}=74.78$ & 0.3 Sodium hypochlorite & $\mathrm{B}_{1}=22.59$ & 69.70 \\
\hline 11. & $\mathrm{~B} 1=63.90$ & 0.4 Sodium hypochlorite & $\mathrm{B} 1=10.87$ & 82.98 \\
\hline 12. & $\mathrm{~B}_{1}=30.73$ & 2 Sodium bisulphate & $\mathrm{B}_{1}=22.12$ & 28.01 \\
\hline 13. & $\mathrm{~B}_{1}=49.20$ & 3 Sodium bisulphate & $\mathrm{B}_{1}=31.0$ & 36.90 \\
\hline 14. & $\mathrm{~B} 1=10.20$ & 99 Acetone & $\mathrm{B}_{1}=3.18$ & 68.82 \\
\hline 15. & $\mathrm{~B}_{1}=25.15$ & 96 Ethanol & $\mathrm{B}_{1}=11.34$ & 54.90 \\
\hline
\end{tabular}

Table 2. Detoxification of aflatoxin B1 in fish feed samples by using different chemicals

\begin{tabular}{|c|c|c|c|c|}
\hline $\begin{array}{l}\text { Fish feed } \\
\text { samples }\end{array}$ & $\begin{array}{l}\text { Aflatoxin B1 } \\
\text { (ppb) }\end{array}$ & $\begin{array}{l}\text { Solvent used for } \\
\text { detoxification } \\
\text { (\%) }\end{array}$ & $\begin{array}{l}\text { Aflatoxin B1 } \\
\text { (ppb) after } \\
\text { treatment }\end{array}$ & $\begin{array}{l}\text { Reduction } \\
\text { in aflatoxin } \\
\text { (\%) }\end{array}$ \\
\hline 1. & $\mathrm{~B}_{1}=4.30$ & 0.1 Hydrochloric acid & $\mathrm{B}_{1}=2.89$ & 32.79 \\
\hline 2. & $\mathrm{~B}_{1}=12.56$ & 0.3 Hydrochloric acid & $\mathrm{B} 1=6.44$ & 48.72 \\
\hline 3. & $\mathrm{~B}_{1}=69.26$ & 0.5 Hydrochloric acid & $\mathrm{B}_{1}=10.46$ & 84.89 \\
\hline 4. & $\mathrm{~B}_{1}=28.65$ & 5 Calcium hydroxide & $\mathrm{B}_{1}=7.68$ & 73.19 \\
\hline 5. & $\mathrm{~B} 1=3.52$ & 50 Calcium hydroxide & $\mathrm{B} 1=0.78$ & 77.84 \\
\hline 6. & $\mathrm{~B}_{1}=46.82$ & 10 Citric acid & $\mathrm{B} 1=31.36$ & 33.02 \\
\hline 7. & $\mathrm{~B}_{1}=10.63$ & 30 Citric acid & $\mathrm{B}_{1}=4.15$ & 60.95 \\
\hline 8. & $\mathrm{~B}_{1}=2.07$ & 1 Iso-propanol & $\mathrm{B}_{1}=2.07$ & 0.00 \\
\hline 9. & $\mathrm{~B}_{1}=1.23$ & 2 Iso-propanol & $\mathrm{B} 1=1.23$ & 0.00 \\
\hline 10. & $\mathrm{~B}_{1}=7.28$ & 5 Iso-propanol & $\mathrm{B}_{1}=6.78$ & 6.86 \\
\hline 11. & $\mathrm{~B}_{1}=6.55$ & 0.3 Sodium hypochlorite & $\mathrm{B}_{1}=2.01$ & 69.31 \\
\hline 12. & $\mathrm{~B}_{1}=25.12$ & 0.4 Sodium hypochlorite & $\mathrm{B}_{1}=4.78$ & 80.97 \\
\hline 13. & $\mathrm{~B}_{1}=23.62$ & 3 Sodium bisulphate & $\mathrm{B} 1=14.89$ & 36.96 \\
\hline 14. & $\mathrm{~B}_{1}=2.40$ & 99 Acetone & $\mathrm{B}_{1}=0.74$ & 69.16 \\
\hline 15. & $\mathrm{~B} 1=13.06$ & 96 Ethanol & $\mathrm{B} 1=6.02$ & 53.90 \\
\hline
\end{tabular}


The sodium hypochlorite concentration and $\mathrm{pH}$ were the most important factors involved in reducing hightoxin levels to non detectable amounts; e.g., at $\mathrm{pH} 8$, $0.4 \%$ sodium hypochlorite reduced aflatoxin $\mathrm{Bl}$ from $725 \mathrm{ppb}$ to trace amounts in ground raw peanuts; at $\mathrm{pH} 9$, only $0.3 \% \mathrm{NaOCl}$ was required (Natarajan et al., 1975). Sodium hypochlorite is chemical substance used with commercial bleaches for detoxification of aflatoxins (Yang, 1972). The results showed a complete destruction of aflatoxin in a very short time when high concentrations of $5-6 \%$ or $0.67 \mathrm{M}$ to $0.81 \mathrm{M}$ of sodium hypochlorite were used.

The maximum detoxification of aflatoxin B1 in poultry feed and fish feed samples was observed when $0.5 \%$ $\mathrm{HCl}$ was used. Acid treatment was the most effective, significantly increasing the ability of tested isolates to remove more aflatoxin B1. These results agree with that reported by El-Nezami et al. (1998), who found that $\mathrm{HCl}$ treatment of $L$. rhamnosus GG and $L$. rhamnosus pellets significantly enhanced the binding ability of it toward aflatoxin B1.

It was concluded that the detoxification of aflatoxin B1 may be affected by alkali solutions according to their concentration but it is degraded greatly by acid addition (WenLi et al., 2008). Strong acids convert aflatoxin to its hemiacetal form through hydration that is much less toxic.

\section{Conclusion}

Aflatoxin contamination is unavoidable and unpredictable which make it unique challenge to feed safety as it directly or indirectly suffers animals and human beings. Although there are many chemicals but it is found that $0.5 \%$ hydrochloric acid is the pre-eminent chemical for decontamination of aflatoxin B1 in poultry and fish feed samples. The study revealed a high incidence of aflatoxin contaminated feed and feed ingredients and that low concentrations of acid removal of AFB1 from feed may be used on large scale to minimize economic loss due aflatoxin contamination and to improve animal health condition.

\section{References}

Alexander, H., Stefan, F., Othmar, K., Hans, D. 2001. Mycotoxin detoxication of animal feed by different adsorbents. Toxicology Letters, 122: 179-188. AOAC. 2005. Official Methods of Analysis of AOAC, $18^{\text {th }}$ edition. 991.31, 994.08: Association of Official Analytical Chemists. Washington DC, USA.
Basappa, S.C., Shantha, T. 1996. Methods for detoxification of aflatoxins in foods and feeds: A critical appraisal. Journal of Food Science and Technology, 33: 95-107.

Bauer, J. 1994. Moglichkeiten zur Entgiftung mykotoxinhaltiger Futtermittel. Monatsh. Veterinarmed, 49: 175-181.

Begum, N., Adil, R., Shah, F.H. 1985. Contamination of groundnuts with Aflatoxins. Pakistan Journal of Medical Research, 24: 129-131.

Bressac, B., Kew, M., Wands, J., Ozturk, M. 1991. Selective $\mathrm{G}$ to T mutation of P53 gene in hepatocellular carcinoma from Southern Africa. Nature, 350: 429-431.

Chiavaro, E.D., Asta, C., Galaverna, G., Biancardi, A., Gambarelli, E., Dossena, A., Marchelli, R. 2001. New reversed-phase liquid chromatographic method to detect aflatoxins in food and feed with cyclodextrins as fluorescence enhancers added to the eluent. Journal of Chromatography A, 937: 31-40.

Coker, R.D., Jones, B.D., Nagler, M.J., Gilman, G.A., Wallbridge, A.J., Panigrahi, S. 1984. Mycotoxin Training Manual,Natural Resources Institute, 29 pp., London, UK.

Dvorak, M. 1990. Possibilities of chemical detoxification of aflatoxins. Veterinary Medicine, 35: 37-42.

El-Nezami, H.S., Kankaanpaa, P., Salminen, S., Ahokas, J.T. 1998. Physico-chemical alterations enhance the ability of dairy strains of lactic acid bacteria to remove aflatoxin from contaminated media. Journal of Food Protection, 61: 466-468.

Frank, T.J. 2011. Reducing the risk of toxic substances in feeds. Feedstuffs, 72-77.

Hamed, K.A. (ed.). 2005. Aflatoxin and Food Safety, pp. 407-421, CRC Press, USDA - ARS, Stoneville, Mississippi, USA.

Natarajan, K.R., Rhee, K.C., Cater, C.M., Mattil, K.F. 1975. Destruction of aflatoxins in peanut protein isolates by sodium hypochlorite. Journal of American Oil Chemical Society, 52: 160-163.

Romer, T.R. 1976. A screening method for aflatoxins in mixed feed and other agriculture commodities. Journal of the Association of Official Analytical Chemists, 59: 110-117.

Safara, M., Zaini, F., Hashemi, S.J., Mahmoudi, M., Khosravi, A. R., Shojai-Aliabadi, F. 2010. Aflatoxin detoxification in rice using citric acid. Iranian Journal of Public Health, 39: 24-29.

Singh, N., Jand, S.K., Baxi, K.K. 2003. Chemical detoxification of aflatoxins in contaminated poultry 
feed. Indian Journal of Animal Sciences, 73: 197199.

Sreenivasa, M.J., Parpia, H.A.B., Srikanta, S., Murti, A.S. 1967. Detoxification of aflatoxin in peanut meal by hydrogen peroxide. Journal of the Association of Official Analytical Chemists, 50: 350-354.

Vieira, S.L. 2003 Nutritional implications of mould development in feedstuffs and alternatives to reduce the mycotoxin problem in feeds. World's Poultry
Science Journal, 59: 111-122.

WenLi, C., Quan, Z., Xing, D. 2008. Chemical detoxification of aflatoxin $\mathrm{B} 1$ in rice by several solutions through fluorescence spectral experiment. Key Engineering Materials, 364: 1032-1036.

Yang, C.Y. 1972. Comparative studies on the detoxification of aflatoxins by sodium hypochlorite and commercial bleaches. Applied Microbiology, 24: 885-890. 